\title{
EVIDENCIAÇÃO DO CAPITAL INTELECTUAL DE NATUREZA SOCIAL E AMBIENTAL: ESTUDO NOS RELATÓRIOS ANUAIS E NOS SITES DAS EMPRESAS LISTADAS NO PROGRAMA 'EM BOA COMPANHIA' DA BOVESPA ${ }^{1}$
}

\author{
DISCLOSURE OF SOCIAL AND ENVIRONMENTAL INTELLECTUAL CAPITAL: A \\ STUDY BASED ON THE ANNUAL REPORTS AND WEBSITES OF COMPANIES \\ LISTED ON THE BOVESPA 'IN GOOD COMPANY' PROGRAM
}

\author{
Harley Almeida Soares da Silva ${ }^{2}$ \\ Suliani Rover ${ }^{3}$ \\ Sandra Rolim Ensslin ${ }^{4}$ \\ Fabricia Silva da Rosa ${ }^{5}$
}

\begin{abstract}
RESUMO: O estudo apresenta os resultados sobre a evidenciação voluntária do Capital Intelectual (CI) de natureza social e ambiental nos Relatórios Anuais e de Sustentabilidade de 2006, denominados neste trabalho como Relatórios Anuais (RAs), e nos sites das 39 empresas integrantes do programa 'Em Boa Companhia' da Bolsa de Valores de São Paulo (BOVESPA). O objetivo do estudo é identificar como é feita a evidenciação do CI de origem social e ambiental, e quais os elementos mais representados nas empresas pesquisadas. Para proceder à análise foram elaboradas duas matrizes de elementos de CI, uma voltada para a perspectiva social, e a outra contemplando a abordagem ambiental. O estudo caracteriza-se como descritivo e documental, a fonte dos dados é de origem secundária, sendo adotada a técnica da análise de conteúdo. Os resultados apontam para uma maior tendência de divulgação dos elementos de origem ambiental. Na análise ambiental, a Estrutura Interna foi a categoria de CI com maior representatividade nas duas fontes de coleta de dados; na análise social dos RAs a Estrutura Interna também predomina; e, por fim, na análise social dos sites a Estrutura Externa destaca-se como a categoria com maior percentual de evidenciação.
\end{abstract}

PALAVRAS-CHAVE: Evidenciação. Capital Intelectual. Natureza Social e Ambiental.

\begin{abstract}
This paper presents the results about voluntary disclosure of social and environmental Intellectual Capital (IC) in the 2006 Annual Reports and Sustainability Reports (henceforth, Annual Reports - ARs), and on the websites of the 39 companies that are listed on the "In Good Company" program of the São Paulo Stock Market (BOVESPA). The purpose of this study is to identify how the disclosure of both types of IC is performed and what elements are most frequently disclosed by the companies assessed. To perform the analysis, two matrices containing IC elements were designed - one for social IC, and another for environmental IC. This is a descriptive study, based on data from a secondary source, employing content analysis. The results indicate that environmental elements tended to be disclosed more frequently than social elements. Among the environmental IC elements, the most recurrent category was Internal Structure, both in the reports and on the websites. The same category is the most frequent in the social analysis of the reports; conversely, External Structure was the social IC category with the highest percentages of disclosure on the websites.
\end{abstract}

KEYWORDS: Disclosure. Intellectual Capital. Social and Environmental Nat.

\footnotetext{
${ }^{1}$ Artigo Recebido em 10.10.2008. Revisado por pares em 05.02.2009. Recomendado em 14.07.2009 por Leomar dos Santos (Editor Adjunto). Publicado em 03.09.2009.

Organização Responsável pelo periódico: Universidade regional de Blumenau - FURB - www.furb.br/rn
}

\footnotetext{
${ }^{2}$ Universidade Federal de Santa Catarina - UFSC - harleyasss@yahoo.com.br

${ }^{3}$ Universidade Federal de Santa Catarina - UFSC - sulianirover@yahoo.com.br

${ }^{4}$ Universidade Federal de Santa Catarina - UFSC - sensslin@gmail.com

${ }^{5}$ Universidade Federal de Santa Catarina - UFSC - fabriciasrosa@hotmail.com
} 


\section{INTRODUÇÃO}

A evidenciação do valor das empresas por meio das tradicionais perspectivas tangíveis, de capital físico e capital financeiro, apresenta-se limitada diante das atuais exigências competitivas impostas às empresas, não observando os demais componentes formadores de valor nas entidades, como o Capital Intelectual (KLEIN, 1998).

Sobre esta visualização restrita decorrente da evidenciação de natureza tangível, Edvinsson e Malone (1998) enfatizam uma preocupação diante da defasagem das informações apresentadas pelos demonstrativos contábeis voltados para a evidenciação tangível, e identificam outro tipo de capital de natureza intangível ou invisível, o Capital Intelectual. Assim, o Capital Intelectual juntamente com o capital físico e financeiro compõem, na atualidade, o capital de uma organização (BRENNAN, 2001; CHEN GOH; PHENG LIM; 2004; ENSSLIN; CARVALHO, 2007). O Capital Intelectual identifica-se como sendo razão de uma economia orientada pelo conhecimento, além de promover vantagens competitivas (SVEIBY, 1998; STEWART, 1998; EDVINSSON; MALONE, 1998; KLEIN, 1998).

Para Kaplan e Norton (2004), esta vantagem competitiva originada por meio da gestão estratégica dos ativos intangíveis pode ser responsável em média por $75 \%$ do valor de mercado de uma empresa. Observe-se que na literatura a terminologia Capital Intelectual (CI) tem sido utilizada, intercambiavelmente, com a terminologia Ativo Intangível (AI); entretanto verifica-se uma tendência de se utilizar o termo AI quando a pesquisa focalizar a Contabilidade Financeira e de se utilizar CI quando a pesquisa focalizar a Contabilidade Gerencial. Neste contexto, este artigo adotará a terminologia Capital Intelectual (CI), uma vez que aborda questões de cunho gerencial.

Entre as inúmeras possibilidades de utilização dos elementos formadores de CI dentro do gerenciamento estratégico das entidades, estes se destacam também como sendo um mecanismo eficiente de gestão e evidenciação de ações ligadas a Responsabilidade Social Empresarial, uma vez que permitem a identificação, correlação e a prestação de contas em relação à postura das entidades perante a sociedade.

Modelos que adotam perspectivas intangíveis, como os propostos pelo Instituto Brasileiro de Análises Sociais e Econômicas (IBASE) e pelo Instituto Ethos de Responsabilidade Social Empresarial, constituem-se mecanismos eficientes de evidenciação e prestação de contas, principalmente quando se trata de questões sociais e ambientais.

A observação das questões pertinentes a Responsabilidade Social Empresarial cada vez mais se faz presente na gestão estratégica das entidades. As empresas ao reconhecerem que suas atividades usufruem os recursos naturais (água, ar, solo, reservas minerais, reservas florestais, etc.) e recursos sociais (mão-de-obra, tecnologia, conhecimento, capital, etc.), devem gerenciar suas ações de tal forma a minimizar/evitar os possíveis danos a esses recursos, ou até mesmo prestar alguma contrapartida a sociedade.

A partir da noção dos custos sociais e ambientais decorrentes das atividades empresariais, a sociedade age por meio de pressões externas que atuam sobre as empresas, tendo como uma de suas finalidades induzirem as entidades a se adequarem aos processos de gestão responsáveis, voltados para as questões sociais, éticas e ambientais (ASHLEY, 2005; SOARES, 2002). Para Soares (2002), o juízo público da empresa é definido por meio destas pressões, sendo que muitas vezes a imagem da empresa pode se sobrepor à marca.

Diante desse contexto, a pesquisa se propõe a analisar os Relatórios Anuais e de Sustentabilidade de 2006, denominados neste estudo como Relatórios Anuais (RAs), e os sites das 39 empresas integrantes do programa 'Em Boa Companhia' da Bolsa de Valores de São Paulo (BOVESPA). Ressalta-se que nesse programa estão listadas empresas que desenvolvem projetos de Responsabilidade Social Empresarial. As ações desenvolvidas por essas empresas 
abrangem áreas de atuação distintas: Ambiental, Capacitação Profissional, Cidadania, Comunidade, Cultural, Educação, Esporte, Saúde e outras. Uma das justificativas relacionadas à importância da evidenciação das ações empresariais voltadas a responsabilidade social e ambiental é que a divulgação de ativos não-financeiros tende a aumentar o valor de mercado de uma empresa, uma vez que a prática afeta positivamente a forma como a instituição é vista e valoriza suas ações (BOVESPA, 2007).

Ao enfatizar a questão dos ativos não-financeiros em função do aumento do valor de mercado de uma companhia e de sua relação com a evidenciação das práticas de caráter responsável, a partir da noção do CI, tem-se a questão norteadora da pesquisa: Como é feita a evidenciação do Capital Intelectual (CI) de natureza social e ambiental em empresas que realizam projetos de Responsabilidade Social Empresarial, e quais os elementos intangíveis mais representados nos RAs e nos sites das companhias pesquisadas? Assim, tem-se como objetivo principal do estudo identificar como é feita a evidenciação do CI de origem social e ambiental, e quais os elementos mais representados nas empresas pesquisadas.

Diante do exposto, apresentam-se os seguintes objetivos específicos da pesquisa: (i) extrair dos Relatórios Anuais e de Sustentabilidade de 2006, e dos sites das empresas, que compõem a amostra, a evidenciação das informações relativas aos elementos de CI de natureza social e ambiental, por meio da técnica da análise de conteúdo; (ii) identificar os elementos mais representativos da amostra, e como esses são evidenciados pelas empresas; (iii) investigar a natureza da evidenciação do CI de natureza social e ambiental; e (iv) cotejar os resultados de divulgação dos elementos de natureza social com os de natureza ambiental.

\title{
2. REFERENCIAL TEÓRICO
}

A base teórica do estudo subdivide-se em duas partes: a primeira faz uma breve conceituação a respeito de Capital Intelectual (CI) e a segunda contempla a perspectiva de Responsabilidade Social e Ambiental adotada neste estudo.

\subsection{Capital Intelectual (CI)}

A Contabilidade durante maior parte de sua trajetória ao longo da história dedicou-se quase que exclusivamente à observação dos componentes patrimoniais tangíveis, compreendidos por capital físico e capital financeiro. No que diz respeito à evidenciação do real valor das entidades, esta perspectiva demonstra-se ultrapassada, pois deixa de observar componentes que agregam valor as empresas, como por exemplo, o conhecimento e as informações.

\begin{abstract}
Sempre existiram lacunas ocasionais e temporárias entre a percepção do mercado e a realidade contábil. Mas, atualmente, esta lacuna está se tornando um abismo. E isso, por sua vez sugere que não estamos examinando uma aberração temporária, mas uma falha sistêmica na maneira como medimos o valor. Trata-se de uma discrepância fundamental entre a história contada nos balanços patrimoniais das corporações e o desempenho real que ocorre diariamente nas próprias organizações (EDVINSSON; MALONE, 1998, p.2).
\end{abstract}

Ao descrever a economia no passado em comparação ao contexto atual, Stewart (1998) lembra o crescimento e os avanços decorrentes da Era Industrial, em que as principais formas de riquezas possuíam a forma ou a procedência física, e as organizações direcionavam seus negócios para atrair capital financeiro. Porém, atualmente, na Era da Informação, as principais riquezas são produtos do conhecimento. 
Conforme corrobora Crawford (1994), na economia do conhecimento, a função do capital físico e financeiro, será o de libertar o potencial humano e elevar a produtividade dos trabalhadores e não a de se tornar o elemento primordial da produção.

O CI configura-se como fruto da Era da Informação, pois o conhecimento em seu aspecto inovador, capaz de agregar valor representa esta categoria de capital, que não apresenta forma material, identificando-se como intangível. Apesar desta característica de ser invisível, o CI pode ser encarado como uma verdadeira revolução, como sugere Stewart (1998), pois através de sua formação as empresas poderão alcançar vantagens competitivas, além de elevar significativamente seu valor.

Em relação às formas básicas de capital que compõe o CI, as propostas de Sveiby (1998), Stewart (1998) e Edvinsson e Malone (1998), apresentam-se fundamentalmente semelhantes, sendo que as maiores distinções seriam as classificações adotadas pelos autores. Salienta-se que neste estudo será adotada a classificação proposta por Sveiby (1998), que divide o CI em três componentes: (i) Competência do Funcionário; (ii) Estrutura Interna; e (iii) Estrutura Externa.

Segundo Sveiby (1998), a primeira categoria, Competência do Funcionário, compreende basicamente a competência, o conhecimento e a capacidade de ação e criação dos funcionários e gestores. $\mathrm{O}$ autor ressalta que embora este capital, também entendido como Capital Humano, não seja de propriedade da empresa, os funcionários que possuem estas competências as disponibilizam voluntariamente à organização.

A cultura organizacional, as patentes, os conceitos, os valores e sistemas administrativos e de computação, apresentam-se como exemplos de elementos que constituem a Estrutura Interna, independentemente destes originarem-se dentro da organização ou terem sido adquiridos em outros lugares. (SVEIBY, 1998).

Assim como o Capital Humano pode ser identificado por ser a fonte do conhecimento de uma organização, o Capital Estrutural apresenta-se como uma espécie de molde desta arquitetura baseada no conhecimento (STEWART, 1998). No ponto de vista de Edvinsson e Malone (1998, p.32), o Capital Estrutural também se caracteriza por ser a "capacidade organizacional, incluindo os sistemas físicos utilizados para transmitir e armazenar conhecimento intelectual".

A Estrutura Externa, conforme Sveiby (1998), inclui as relações externas a entidade, como a marca, a reputação ou a imagem da empresa. Entre os fatores que atuam na formação da Estrutura Externa, possivelmente o intercambio de conhecimento apresenta-se como um dos mais eficientes. Para Stewart (1998, p. 70), "o conhecimento compartilhado é a forma máxima do capital de clientes". O intercambio de conhecimento entre os indivíduos de uma organização, com os seus clientes, fornecedores ou até mesmo com a comunidade, pode proporcionar redes de relacionamento e de satisfação que atuam potencializando o valor atribuído a este tipo de capital, além de proporcionar a troca de experiências entre os funcionários e gestores da organização com os grupos externos (SVEIBY, 1998).

Uma receita gerada por meio do CI pode apresentar parcelas de contribuição entre as três categorias que o compõe. Stewart (1998) afirma que o CI não é criado através de partes distintas de Capital Humano, Estrutural e de Clientes, mas do intercâmbio entre eles. Portanto, o CI é resultado da gestão estratégica conjunta dessas três categorias.

\subsection{Responsabilidade Social e Ambiental}

A observação das questões relacionadas à postura responsável a partir das perspectivas sociais e ambientais apresenta-se como uma das preocupações centrais para as organizações que almejem crescer em harmonia com a sociedade e a natureza. (ASHLEY, 2005). Campos e 
Lemes (2007) destacam que as carteiras de investimentos do mercado de capitais cada vez mais incorporam o conceito de investimento socialmente responsável. No caso brasileiro, a BOVESPA possui o Índice de Sustentabilidade Empresarial que é composto por empresas que se comprometem com responsabilidade social e ambiental e a sustentabilidade empresarial.

O engajamento das organizações em promover ações de cunho social, voltadas para os aspectos éticos e de filantropia, além da preocupação com a cidadania e justiça social, são fatores integrantes da esfera da Responsabilidade Social (ASHLEY, 2005).

\begin{abstract}
Ser socialmente responsável implica para a empresa valorizar seus empregados, respeitar os direitos dos acionistas, manter relações de boa conduta com seus clientes e fornecedores, manter ou apoiar programas de preservação ambiental, atender à legislação pertinente à sua atividade, recolher impostos, apoiar ou manter ações que visem diminuir ou eliminar problemas sociais nas áreas de saúde e educação e fornecer informações sobre sua atividade. Em resumo, a empresa deve ter os conceitos de ética e transparência como os princípios de sua conduta (ASHLEY, 2005, p.173)
\end{abstract}

Dentro do conjunto de temas que abrangem a compreensão de Responsabilidade Social Empresarial, as questões ambientais certamente destacam-se a ponto de demandarem uma atenção especial, principalmente pelo fato das transformações ambientais (clima, poluição, desmatamento, risco de extinção de espécies animais e vegetais, entre outros fatores) apresentam-se perceptivas para toda a sociedade. Diante deste cenário, as organizações tendem a incorporar as suas atividades medidas que procurem atender as políticas no âmbito da responsabilidade ambiental.

Seiffert (2005) destaca que fatores como a competitividade, as pressões dos agentes externos às organizações e a preocupação com a imagem da empresa como ecologicamente correta, configuram-se como algumas das variáveis relevantes para que uma empresa almeje adotar práticas direcionadas a responsabilidade ambiental. Do mesmo modo, o campo da responsabilidade ambiental compreende a postura adotada pelas organizações em desenvolver e conduzir ações que promovam a redução dos impactos ambientais de suas atividades.

Um dos grandes dilemas enfrentados atualmente pelas organizações encontra-se na necessidade da promoção do desenvolvimento sustentável (SEIFFERT, 2005). Para tal, Schenini (2005) aponta que seja imprescindível o alinhamento entre as estratégias ambientais adotadas pelas empresas com a execução do Planejamento Estratégico Sustentável. O autor ainda enfatiza que por meio do desenvolvimento destas práticas administrativas voltadas para a sustentabilidade, a empresa poderia identificar seus pontos fortes e fracos internos voltados ao tema, assim como os aspectos externos à entidade que possam gerar ameaças ou oportunidades relacionadas a questões ambientais.

Silva Filho (2007) identifica o exercício da Responsabilidade Sócio-Ambiental como um elemento que se apresenta no centro da esfera de governo da organização, em que a adoção da postura da sustentabilidade, ligada à vontade da preservação do meio ambiente no âmbito interno da organização pode impulsionar o desenvolvimento no âmbito macro-social.

\title{
3. METODOLOGIA
}

O presente trabalho, quanto aos seus objetivos, classifica-se como descritivo, pois expõe os componentes do fenômeno estudado, em que se descreve, registra, analisa e correlaciona os dados (CERVO; BERVIAN, 1983).

A pesquisa faz uso de uma abordagem qualitativa, uma vez que analisa os elementos de CI de natureza social e ambiental. Segundo Richardson (1999), por meio das técnicas qualitativas, é possível interpretar os resultados e ampliar o conhecimento; o que será feito 
nesta pesquisa ao identificar qual elemento e qual categoria é mais evidenciado; observe-se, assim, que os objetivos específicos formulados nesta pesquisa são analisados sob a perspectiva qualitativa. As fontes utilizadas no estudo são de origem secundária (RICHARDSON, 1999), uma vez que os dados são extraídos dos sites das empresas pesquisadas e dos Relatórios Anuais e de Sustentabilidade.

O procedimento técnico utilizado será a pesquisa documental, já que a análise dos Relatórios Anuais e de Sustentabilidade e dos sites das empresas apresentam-se como fontes para a posterior identificação dos elementos de CI de natureza social e ambiental evidenciados pelas empresas integrantes da amostra.

Para realizar a coleta e interpretação dos dados nos relatórios e nos sites pesquisados faz-se necessária à utilização da técnica da análise de conteúdo. Para Bardin (2004), a análise de conteúdo é um conjunto de técnicas de análise das comunicações, que utiliza procedimentos sistemáticos e objetivos de descrição do conteúdo das mensagens. Puglisi e Franco (2005) afirmam que para se proceder a análise de conteúdo, necessariamente, deve-se identificar a unidade de registro que se irá investigar, sendo essa identificação indispensável à análise e interpretação dos textos a serem decodificados e, sobretudo, para que se possa estabelecer a diferenciação resultante dos conceitos de significado e sentido. Neste artigo a unidade de registro selecionada foi a sentença.

\subsection{População e Amostra}

A população da pesquisa abrange as empresas listadas na BOVESPA e a amostra do estudo é composta pelas 39 empresas integrantes do programa "Em Boa Companhia" também da BOVESPA, conforme a Ilustração 1.

\begin{tabular}{|c|l|r|l|l|l|}
\hline 1 & ALL & 14 & CPFL Energia & 27 & Natura Cosméticos \\
\hline 2 & Aracruz Celulose & 15 & CSU Cardsystem & 28 & OHL Brasil \\
\hline 3 & Banco Bradesco & 16 & Cyrela Brazil Realty & 29 & Porto Seguro \\
\hline 4 & Banco do Brasil & 17 & Diagnósticos da América & 30 & Sabesp \\
\hline 5 & Braskem & 18 & Dixie Toga & 31 & Sanepar \\
\hline 6 & Cataguazes - Leopoldina & 19 & Duke Energy & 32 & Souza Cruz \\
\hline 7 & CCR & 20 & Duratex & 33 & Suzano Papel e Celulose \\
\hline 8 & Celesc & 21 & Energias do Brasil & 34 & Suzano Petroquímica \\
\hline 9 & Celulose Irani & 22 & Gerdau & 35 & TAM Linhas Aéreas \\
\hline 10 & Cemig & 23 & Grupo Pão de Açúcar & 36 & Ultrapar Participações \\
\hline 11 & Coelce & 24 & Invepar & 37 & Unibanco \\
\hline 12 & Companhia Vale do Rio Doce & 25 & Itaú & 38 & Votorantim Celulose e Papel \\
\hline 13 & Copel & 26 & MAHLE Metal Leve & 39 & WEG \\
\hline
\end{tabular}

Fonte: Dados da Pesquisa

Ilustração 1: Amostra da pesquisa

\subsection{Fonte de Coleta dos Dados}

A coleta dos dados dos elementos de CI de natureza social e ambiental foi realizada em duas etapas: (i) coleta dos dados nos Relatórios Anuais e/ou de Sustentabilidade; e (ii) coleta dos dados nos sites das empresas.

$\mathrm{Na}$ primeira etapa os dados foram coletados nos Relatórios Anuais e/ou de Sustentabilidade. Salienta-se que em algumas empresas foram encontrados apenas um dos relatórios. Em outros casos, apresentavam-se os dois formatos de relatórios investigados. Nessas situações, a pesquisa restringiu-se a análise dos relatórios disponibilizados pelas 
empresas. Vale ressaltar que este estudo se reportará aos dois formatos de relatórios por meio da denominação Relatórios Anuais (RAs).

$\mathrm{Na}$ segunda etapa da coleta, os elementos foram extraídos dos sites das empresas. Adverte-se que os sites pesquisados incluíram inclusive àqueles dos institutos ou fundações que pertençam a alguma empresa que componha a amostra.

\subsection{Procedimentos para Registro e Análise dos Dados}

Para proceder a identificação dos elementos da pesquisa, utilizou-se a metodologia de análise de conteúdo adaptada de Guthrie et al. (1999 apud CARVALHO, ENSSLIN, IGARASHI, 2006). O presente estudo fará uso apenas dos códigos: $0=$ item não apareceu no Relatório Anual; e 1 = item apareceu no Relatório Anual em forma narrativa. Para o registro e posterior tabulação dos dados foi utilizada a classificação de Sveiby (1998) no que diz respeito às categorias: Competência dos Funcionários, Estrutura Interna e Estrutura Externa.

No que tange a classificação dos elementos, como a proposta de Sveiby (1998) não contempla a perspectiva do CI pelo ponto de vista da Responsabilidade Social e Ambiental, foram elaboradas duas matrizes (Tabelas 1 e 2) de elementos, a partir da literatura relacionada à Responsabilidade Social Empresarial. A primeira tabela contempla a perspectiva de CI de origem social; e, a segunda tabela está direcionada a perspectiva de CI sob a ótica ambiental.

Tabela 1: Matriz de elemento de CI de origem social

\begin{tabular}{|c|c|c|c|c|c|c|c|}
\hline \multirow{2}{*}{\multicolumn{2}{|c|}{ Elementos de Capital Intelectual Social }} & \multicolumn{2}{|c|}{$\begin{array}{c}\text { Empresa } \\
1 \\
\end{array}$} & \multicolumn{2}{|c|}{$\begin{array}{c}\text { Empresa } \\
\ldots \\
\end{array}$} & \multicolumn{2}{|c|}{$\begin{array}{c}\text { Empresa } \\
39 \\
\end{array}$} \\
\hline & & RA & site & RA & site & RA & site \\
\hline \multicolumn{8}{|c|}{ Competência do Funcionário } \\
\hline 1 & Educação ou aprendizado social & & & & & & \\
\hline 2 & Conhecimento de práticas responsáveis & & & & & & \\
\hline 3 & Competências relacionadas ao trabalho com a Responsabilidade Social & & & & & & \\
\hline 4 & Conscientização Social (Voluntariado) & & & & & & \\
\hline 5 & Atividades Esportivas & & & & & & \\
\hline 6 & Atividades Culturais & & & & & & \\
\hline 7 & Atividades Artísticas & & & & & & \\
\hline 8 & Atividades de Lazer & & & & & & \\
\hline 9 & Qualificação vocacional & & & & & & \\
\hline \multicolumn{8}{|c|}{ Estrutura Interna } \\
\hline 10 & Cultura Organizacional Responsável & & & & & & \\
\hline 11 & Código de Ética ou de Conduta & & & & & & \\
\hline 12 & Integração dos colaboradores & & & & & & \\
\hline 13 & Segurança e saúde no trabalho & & & & & & \\
\hline 14 & Práticas trabalhistas & & & & & & \\
\hline \multicolumn{8}{|c|}{ Estrutura Externa } \\
\hline 15 & Ligação da Marca com a Responsabilidade Social & & & & & & \\
\hline 16 & Conscientização social dos Clientes & & & & & & \\
\hline 17 & Vinculação do nome ou da imagem com ações sociais & & & & & & \\
\hline 18 & Integração e parcerias com a Comunidade & & & & & & \\
\hline 19 & Participação em Comunidades Carentes & & & & & & \\
\hline 20 & Atividades com povos indígenas & & & & & & \\
\hline 21 & Projetos e ações de inclusão social & & & & & & \\
\hline 22 & Projetos e ações de valorização da diversidade racial & & & & & & \\
\hline 23 & Projetos e ações de incentivo a práticas esportivas & & & & & & \\
\hline 24 & Projetos e ações de incentivo a práticas culturais & & & & & & \\
\hline 25 & Projetos e ações de incentivo a práticas artísticas & & & & & & \\
\hline
\end{tabular}

Revista de Negócios, ISSN 1980-4431, Blumenau, v. 14, n. 1 p. 82 - 99, Janeiro/Março 2009. 
26 Projetos e ações de incentivo a práticas educacionais

27 Projetos e ações de incentivo a práticas de lazer

Total

Fonte: Dados da Pesquisa

Conforme Tabela 1 verifica-se que 27 elementos de natureza social serão investigados nos relatórios e nos sites das empresas. A Tabela 2 apresenta os elementos de CI de origem ambiental considerados para o presente estudo.

Tabela 2: Matriz de elemento de CI de origem ambiental

\begin{tabular}{|c|c|c|c|c|c|c|c|}
\hline \multirow{2}{*}{\multicolumn{2}{|c|}{ Elementos de Capital Intelectual Ambiental }} & \multicolumn{2}{|c|}{$\begin{array}{c}\text { Empresa } \\
1 \\
\end{array}$} & \multicolumn{2}{|c|}{$\begin{array}{c}\text { Empresa } \\
\ldots \\
\end{array}$} & \multicolumn{2}{|c|}{$\begin{array}{c}\text { Empresa } \\
39 \\
\end{array}$} \\
\hline & & RA & site & RA & site & RA & site \\
\hline \multicolumn{8}{|c|}{ Competência do funcionário } \\
\hline 1 & Educação ou aprendizado ambiental & & & & & & \\
\hline 2 & Conhecimento de práticas de responsabilidade ambiental & & & & & & \\
\hline 3 & Competências relacionadas ao trabalho com a Responsabil. Ambiental & & & & & & \\
\hline 4 & Conscientização Ambiental & & & & & & \\
\hline \multicolumn{8}{|c|}{ Estrutura Interna } \\
\hline 5 & Processos de Gestão Sustentáveis & & & & & & \\
\hline 6 & Proc. de Captação e Minimização da emissão de resíduos (Reciclagem) & & & & & & \\
\hline \multicolumn{8}{|c|}{ Estrutura Externa } \\
\hline 7 & Ligação da Marca com a Responsabilidade Ambiental & & & & & & \\
\hline 8 & Conscientização ambiental dos Clientes & & & & & & \\
\hline 9 & Vinculação do nome ou da imagem com ações ambientais & & & & & & \\
\hline 10 & Integração e parcerias com a Comunidade & & & & & & \\
\hline 11 & Postura sustentável & & & & & & \\
\hline \multicolumn{2}{|c|}{ Total } & & & & & & \\
\hline
\end{tabular}

Fonte: Dados da Pesquisa

A análise de conteúdo procederá da seguinte forma: quando algum dos elementos for detectado nos RAs, passa a ser sinalizado na matriz correspondente com o número 1; este procedimento é adotado para todas as 39 empresas que compõem a amostra para a posterior identificação dos elementos mais evidenciados nas empresas. O mesmo procedimento é adotado para a identificação dos elementos nos sites.

\section{APRESENTAÇÃO E DISCUSSÃO DOS RESULTADOS}

\subsection{Evidenciação do CI de Natureza Social}

$\mathrm{Na}$ amostra pesquisada, praticamente todas as empresas apresentaram evidenciação voluntária de algum tipo de elemento de CI de origem social. Do total de 39 empresas analisadas, apenas a empresa Dixie Toga não evidenciou elementos de CI nos RAs, todavia, divulgou 13 elementos no site. Essa postura de evidenciação demonstra que as empresas, embora não exista a obrigatoriedade de divulgação desses elementos, estão tendo a percepção de que a evidenciação é fator estratégico e de suma importância para as mesmas.

A Tabela 3 evidencia os resultados obtidos por empresa no que se refere ao CI de origem social, em termos numéricos e percentuais. 
Tabela 3: Comparação entre os resultados obtidos na análise social

\begin{tabular}{|c|c|c|c|c|c|}
\hline \multicolumn{2}{|c|}{ Empresas da Amostra } & $\begin{array}{c}\text { Resultados } \\
\text { Social - RAs }\end{array}$ & $\begin{array}{l}\text { Percentuais } \\
\text { Social - RAs }\end{array}$ & $\begin{array}{c}\text { Resultados } \\
\text { Social - Sites }\end{array}$ & $\begin{array}{l}\text { Percentuais } \\
\text { Social - Sites }\end{array}$ \\
\hline 1 & ALL & 12 & $44 \%$ & 13 & $48 \%$ \\
\hline 2 & Aracruz Celulose & 15 & $56 \%$ & 11 & $41 \%$ \\
\hline 3 & Banco Bradesco & 17 & $63 \%$ & 14 & $52 \%$ \\
\hline 4 & Banco do Brasil & 14 & $52 \%$ & 15 & $56 \%$ \\
\hline 5 & Braskem & 15 & $56 \%$ & 7 & $26 \%$ \\
\hline 6 & Cataguazes-Leopoldina & 11 & $41 \%$ & 5 & $19 \%$ \\
\hline 7 & CCR & 15 & $56 \%$ & 6 & $22 \%$ \\
\hline 8 & Celesc & 11 & $41 \%$ & 13 & $48 \%$ \\
\hline 9 & Celulose Irani & 18 & $67 \%$ & 8 & $30 \%$ \\
\hline 10 & Cemig & 14 & $52 \%$ & 11 & $41 \%$ \\
\hline 11 & Coelce & 14 & $52 \%$ & 8 & $30 \%$ \\
\hline 12 & Companhia Vale do Rio Doce & 15 & $56 \%$ & 18 & $67 \%$ \\
\hline 13 & Copel & 18 & $67 \%$ & 11 & $41 \%$ \\
\hline 14 & CPFL Energia & 15 & $56 \%$ & 10 & $37 \%$ \\
\hline 15 & CSU Cardsystem & 11 & $41 \%$ & 9 & $33 \%$ \\
\hline 16 & Cyrela Brazil Realty & 4 & $15 \%$ & 1 & $4 \%$ \\
\hline 17 & Diagnósticos da América & 10 & $37 \%$ & 6 & $22 \%$ \\
\hline 18 & Dixie Toga & 0 & $0 \%$ & 13 & $48 \%$ \\
\hline 19 & Duke Energy & 9 & $33 \%$ & 9 & $33 \%$ \\
\hline 20 & Duratex & 10 & $37 \%$ & 8 & $30 \%$ \\
\hline 21 & Energias do Brasil & 15 & $56 \%$ & 16 & $59 \%$ \\
\hline 22 & Gerdau & 11 & $41 \%$ & 13 & $48 \%$ \\
\hline 23 & Grupo Pão de Açúcar & 14 & $52 \%$ & 8 & $30 \%$ \\
\hline 24 & Invepar & 12 & $44 \%$ & 12 & $44 \%$ \\
\hline 25 & Itaú & 11 & $41 \%$ & 10 & $37 \%$ \\
\hline 26 & MAHLE Metal Leve & 10 & $37 \%$ & 7 & $26 \%$ \\
\hline 27 & Natura Cosméticos & 20 & $74 \%$ & 10 & $37 \%$ \\
\hline 28 & OHL Brasil & 12 & $44 \%$ & 4 & $15 \%$ \\
\hline 29 & Porto Seguro & 11 & $41 \%$ & 11 & $41 \%$ \\
\hline 30 & Sabesp & 13 & $48 \%$ & 13 & $48 \%$ \\
\hline 31 & Sanepar & 8 & $30 \%$ & 2 & $7 \%$ \\
\hline 32 & Souza Cruz & 11 & $41 \%$ & 13 & $48 \%$ \\
\hline 33 & Suzano Papel e Celulose & 17 & $63 \%$ & 12 & $44 \%$ \\
\hline 34 & Suzano Petroquímica & 11 & $41 \%$ & 8 & $30 \%$ \\
\hline 35 & TAM Linhas Aéreas & 8 & $30 \%$ & 13 & $48 \%$ \\
\hline 36 & Ultrapar Participações & 12 & $44 \%$ & 8 & $30 \%$ \\
\hline 37 & Unibanco & 13 & $48 \%$ & 10 & $37 \%$ \\
\hline 38 & VCP - Votorantim Celulose e Papel & 15 & $56 \%$ & 11 & $41 \%$ \\
\hline 39 & WEG & 1 & $4 \%$ & 14 & $52 \%$ \\
\hline
\end{tabular}

Fonte: Dados da Pesquisa

Das 39 empresas pesquisadas, 25 apresentaram uma quantidade maior de elementos evidenciados por meio dos RAs, demonstrando que esta forma de evidenciação identifica-se como a predominante na análise dos elementos de CI de origem social. A evidenciação disponibilizada nos sites mostrou-se mais eficiente em dez empresas (ALL, Banco do Brasil, Celesc, Companhia Vale do Rio Doce, Dixie Toga, Energias do Brasil, Gerdau, Souza Cruz, TAM e WEG), sendo que em quatro empresas (Duke Energy, Invepar, Porto Seguro e Sabesp) ocorreu empate no número de elementos evidenciados nas duas fontes de pesquisa. 


\subsubsection{Evidenciação dos Elementos de Natureza Social}

Observe-se que a matriz de elementos sociais possui 27 elementos subdivididos nas três categorias que compõe o CI, distribuídos da seguinte forma: nove elementos na Competência do Funcionário, cinco elementos na Estrutura Interna e 13 elementos na Estrutura Externa. Caso o total na última linha da matriz social, tanto na análise dos RAs quanto na dos sites, fosse igual a 1053 elementos evidenciados $(27$ elementos sociais x 39 empresas), corresponderia a 100\% de evidenciação de elementos sociais. Os resultados totais por elementos sociais apresentam-se na Tabela 4, assim como o percentual de evidenciação total por elemento.

Tabela 4: Resultados da análise dos elementos de CI de origem social

\begin{tabular}{|c|c|c|c|c|c|}
\hline \multirow{2}{*}{\multicolumn{2}{|c|}{ Elementos de Capital Intelectual Social }} & \multicolumn{2}{|c|}{ Total } & \multicolumn{2}{|c|}{$\%$} \\
\hline & & \multirow[t]{2}{*}{ RAs } & \multirow[t]{2}{*}{ Sites } & \multirow[t]{2}{*}{ RAs } & \multirow[t]{2}{*}{ Sites } \\
\hline Cor & mpetência do Funcionário & & & & \\
\hline 1 & Educação ou aprendizado social & 32 & 21 & $82 \%$ & $54 \%$ \\
\hline 2 & Conhecimento de práticas responsáveis & 9 & 4 & $23 \%$ & $10 \%$ \\
\hline 3 & Competências relacionando o trabalho com a Responsabilidade Social & 12 & 2 & $31 \%$ & $5 \%$ \\
\hline 4 & Conscientização Social (Voluntariado) & 29 & 23 & $74 \%$ & $59 \%$ \\
\hline 5 & Atividades Esportivas & 9 & 8 & $23 \%$ & $21 \%$ \\
\hline 6 & Atividades Culturais & 5 & 6 & $13 \%$ & $15 \%$ \\
\hline 7 & Atividades Artísticas & 1 & 1 & $3 \%$ & $3 \%$ \\
\hline 8 & Atividades de Lazer & 5 & 5 & $13 \%$ & $13 \%$ \\
\hline 9 & Qualificação vocacional & 35 & 28 & $90 \%$ & $72 \%$ \\
\hline \multicolumn{6}{|c|}{ Estrutura Interna } \\
\hline 10 & Cultura Organizacional Responsável & 16 & 13 & $41 \%$ & $33 \%$ \\
\hline 11 & Código de Ética ou de Conduta & 24 & 22 & $62 \%$ & $56 \%$ \\
\hline 12 & Integração dos colaboradores & 13 & 5 & $33 \%$ & $13 \%$ \\
\hline 13 & Segurança e saúde no trabalho & 33 & 26 & $85 \%$ & $67 \%$ \\
\hline 14 & Práticas trabalhistas & 8 & 0 & $21 \%$ & $0 \%$ \\
\hline \multicolumn{6}{|c|}{ Estrutura Externa } \\
\hline 15 & Ligação da Marca com a Responsabilidade Social & 6 & 2 & $15 \%$ & $5 \%$ \\
\hline 16 & Conscientização social dos Clientes & 29 & 28 & $74 \%$ & $72 \%$ \\
\hline 17 & Vinculação do nome ou da imagem com ações sociais & 9 & 2 & $23 \%$ & $5 \%$ \\
\hline 18 & Integração e parcerias com a Comunidade & 36 & 37 & $92 \%$ & $95 \%$ \\
\hline 19 & Participação em Comunidades Carentes & 21 & 23 & $54 \%$ & $59 \%$ \\
\hline 20 & Atividades com povos indígenas & 5 & 2 & $13 \%$ & $5 \%$ \\
\hline 21 & Projetos e ações de inclusão social & 22 & 25 & $56 \%$ & $64 \%$ \\
\hline 22 & Projetos e ações de valorização da diversidade racial & 3 & 3 & $8 \%$ & $8 \%$ \\
\hline 23 & Projetos e ações de incentivo a práticas esportivas & 13 & 12 & $33 \%$ & $31 \%$ \\
\hline 24 & Projetos e ações de incentivo a práticas culturais & 31 & 28 & $79 \%$ & $72 \%$ \\
\hline 25 & Projetos e ações de incentivo a práticas artísticas & 22 & 19 & $56 \%$ & $49 \%$ \\
\hline 26 & Projetos e ações de incentivo a práticas educacionais & 37 & 37 & $95 \%$ & $95 \%$ \\
\hline 27 & Projetos e ações de incentivo a práticas de lazer & 8 & 9 & $21 \%$ & $23 \%$ \\
\hline \multicolumn{2}{|r|}{ Total } & 473 & 391 & & \\
\hline
\end{tabular}

Fonte: Dados da Pesquisa

Revista de Negócios, ISSN 1980-4431, Blumenau, v. 14, n. 1 p. 82 - 99, Janeiro/Março 2009. 
O total obtido na coluna dos RAs foi de 473 elementos, correspondendo a $45 \%$ de evidenciação total dos elementos de origem social. No caso dos sites o total identificado foi de 391 elementos, equivalente a 37\% de evidenciação total dos elementos de origem social.

Percebe-se que a evidenciação voluntária dos elementos de CI de natureza social pelas empresas não é expressiva em relação aos elementos delineados, uma vez que a evidenciação não contempla $50 \%$ dos elementos. No que tange a fonte de evidenciação, pode-se inferir que a evidenciação por meio dos RAs foi mais utilizada pelas empresas.

Em linhas gerais, verifica-se que o elemento mais evidenciado foi 'Projetos e ações de incentivo a práticas educacionais', seguindo pelo elemento 'Integração e parcerias com a Comunidade'. Os elementos menos evidenciados são 'Atividades Artísticas' e 'Projetos e ações de valorização da diversidade racial'.

\subsubsection{Evidenciação dos Elementos de Natureza Social por Categoria de CI}

A Estrutura Interna apresenta-se como a categoria de CI mais representativa na evidenciação dos elementos de origem social nos RAs, com 36\% do total identificado. Ressalta-se que a Estrutura Externa apontou uma evidenciação de 35\%, caracterizando praticamente um empate entre as duas categorias. A Competência dos Funcionários ficou em terceiro lugar com $29 \%$ dos elementos divulgados na análise social dos RAs.

A parcela de representatividade obtida por categoria de CI obtida na análise social dos RAs e nos sites é ilustrada na Ilustração 2.

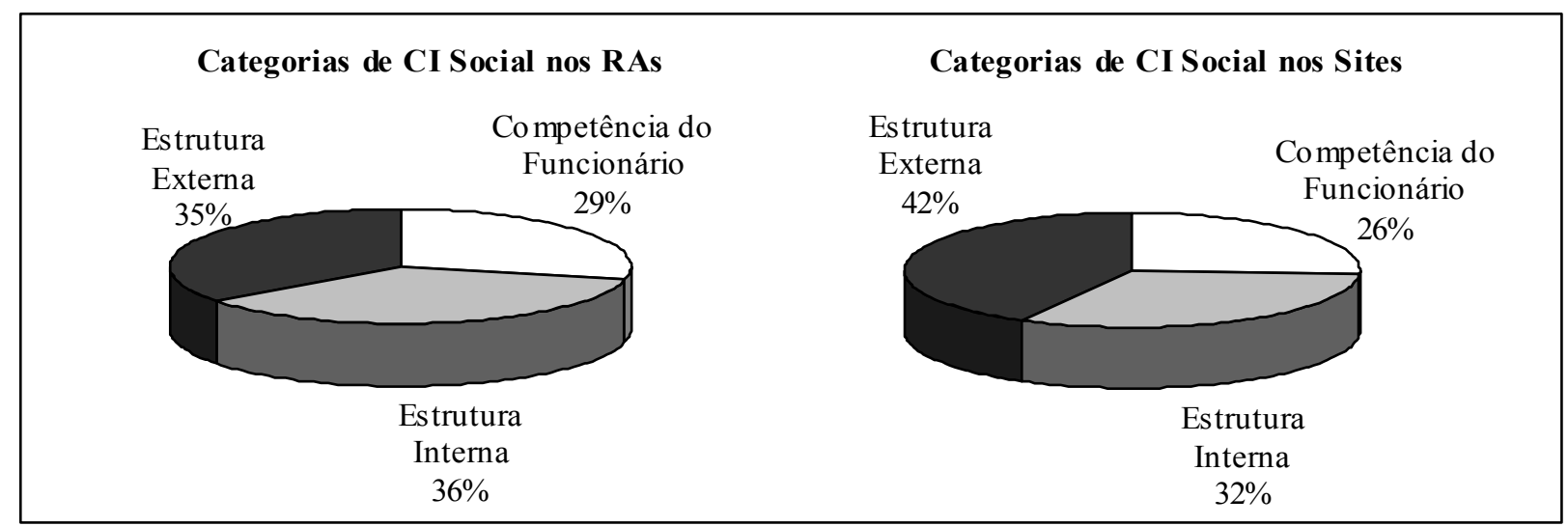

Gráfico 2: Representatividade por categoria de CI na análise social dos RAs e dos sites Fonte: Dados da Pesquisa

Na evidenciação dos elementos de CI de origem social por meio dos sites, a Estrutura Externa caracteriza-se como a categoria mais representativa com $42 \%$ do total identificado; seguida pela categoria Estrutura Interna com 32\%; o que indica uma inversão das posições verificadas na análise dos RAs. A Competência dos Funcionários manteve-se em terceiro lugar com $26 \%$ dos elementos evidenciados, sugerindo ainda uma perda de representatividade em comparação a análise de CI de natureza social dos RAs.

Na seqüência, apresentam-se os resultados obtidos na análise ambiental dos RAs e dos sites das empresas analisadas. 


\subsection{Evidenciação do CI de Natureza Ambiental}

Do total de 39 empresas da amostra, somente a empresa Dixie Toga não evidenciou elementos de CI nos RAs. Vale ressaltar que apesar da empresa mencionada não divulgar informações a respeito do CI de natureza ambiental nos relatórios, esta evidenciou cinco elementos no seu site. No que se refere à análise dos sites, não foram detectados os elementos de natureza ambiental em quatro empresas da amostra: Cataguazes-Leopoldina, CCR, CSU Cardsystem, e Cyrela Brazil Realty. Apesar da não obrigatoriedade da evidenciação destes elementos por parte das empresas, a postura adotada demonstra a preocupação com a questão da divulgação de informações relativas ao meio ambiente. Os resultados por empresa em termos numéricos e percentuais são demonstrados na Tabela 5.

Tabela 5: Comparação entre os resultados obtidos na análise ambiental

\begin{tabular}{|c|c|c|c|c|c|}
\hline \multicolumn{2}{|c|}{ Empresas da Amostra } & \multirow{2}{*}{ 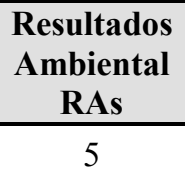 } & \multirow{2}{*}{$\begin{array}{c}\begin{array}{c}\text { Percentuais } \\
\text { Ambiental } \\
\text { RAs }\end{array} \\
45 \%\end{array}$} & \multirow{2}{*}{$\begin{array}{c}\begin{array}{c}\text { Resultados } \\
\text { Ambiental } \\
\text { Sites }\end{array} \\
7\end{array}$} & \multirow{2}{*}{$\begin{array}{c}\text { Percentuais } \\
\begin{array}{c}\text { Ambiental } \\
\text { Sites }\end{array} \\
64 \%\end{array}$} \\
\hline 1 & ALL & & & & \\
\hline 2 & Aracruz Celulose & 8 & $73 \%$ & 7 & $64 \%$ \\
\hline 3 & Banco Bradesco & 7 & $64 \%$ & 7 & $64 \%$ \\
\hline 4 & Banco do Brasil & 2 & $18 \%$ & 3 & $27 \%$ \\
\hline 5 & Braskem & 7 & $64 \%$ & 5 & $45 \%$ \\
\hline 6 & Cataguazes-Leopoldina & 4 & $36 \%$ & 0 & $0 \%$ \\
\hline 7 & CCR & 8 & $73 \%$ & 0 & $0 \%$ \\
\hline 8 & Celesc & 7 & $64 \%$ & 5 & $45 \%$ \\
\hline 9 & Celulose Irani & 7 & $64 \%$ & 5 & $45 \%$ \\
\hline 10 & Cemig & 6 & $55 \%$ & 7 & $64 \%$ \\
\hline 11 & Coelce & 7 & $64 \%$ & 7 & $64 \%$ \\
\hline 12 & Companhia Vale do Rio Doce & 7 & $64 \%$ & 7 & $64 \%$ \\
\hline 13 & Copel & 7 & $64 \%$ & 8 & $73 \%$ \\
\hline 14 & CPFL Energia & 7 & $64 \%$ & 7 & $64 \%$ \\
\hline 15 & CSU Cardsystem & 2 & $18 \%$ & 0 & $0 \%$ \\
\hline 16 & Cyrela Brazil Realty & 2 & $18 \%$ & 0 & $0 \%$ \\
\hline 17 & Diagnósticos da América & 7 & $64 \%$ & 5 & $45 \%$ \\
\hline 18 & Dixie Toga & 0 & $0 \%$ & 5 & $45 \%$ \\
\hline 19 & Duke Energy & 5 & $45 \%$ & 4 & $36 \%$ \\
\hline 20 & Duratex & 6 & $55 \%$ & 7 & $64 \%$ \\
\hline 21 & Energias do Brasil & 8 & $73 \%$ & 6 & $55 \%$ \\
\hline 22 & Gerdau & 6 & $55 \%$ & 7 & $64 \%$ \\
\hline 23 & Grupo Pão de Açúcar & 5 & $45 \%$ & 4 & $36 \%$ \\
\hline 24 & Invepar & 5 & $45 \%$ & 5 & $45 \%$ \\
\hline 25 & Itaú & 3 & $27 \%$ & 6 & $55 \%$ \\
\hline 26 & MAHLE Metal Leve & 5 & $45 \%$ & 5 & $45 \%$ \\
\hline 27 & Natura Cosméticos & 10 & $91 \%$ & 9 & $82 \%$ \\
\hline 28 & OHL Brasil & 8 & $73 \%$ & 2 & $18 \%$ \\
\hline 29 & Porto Seguro Cia. de Seguros Gerais & 3 & $27 \%$ & 2 & $18 \%$ \\
\hline 30 & Sabesp & 6 & $55 \%$ & 5 & $45 \%$ \\
\hline 31 & Sanepar & 6 & $55 \%$ & 5 & $45 \%$ \\
\hline
\end{tabular}




\begin{tabular}{l|l|l|l|l|l}
\hline 32 & Souza Cruz & 4 & $36 \%$ & 6 & $55 \%$ \\
33 & Suzano Papel e Celulose & 6 & $55 \%$ & 7 & $64 \%$ \\
34 & Suzano Petroquímica & 7 & $64 \%$ & 5 & $45 \%$ \\
35 & TAM Linhas Aéreas & 2 & $18 \%$ & 3 & $27 \%$ \\
36 & Ultrapar Participações & 4 & $36 \%$ & 4 & $36 \%$ \\
37 & Unibanco & 4 & $36 \%$ & 5 & $45 \%$ \\
38 & VCP - Votorantim Celulose e Papel & 7 & $64 \%$ & 6 & $55 \%$ \\
39 & WEG & 3 & $27 \%$ & 5 & \\
\hline Fo
\end{tabular}

Fonte: Dados da Pesquisa

Em 19 empresas da amostra os RAs apresentaram-se como o meio mais utilizado para a evidenciação dos elementos intangíveis de natureza ambiental, seguindo a mesma tendência observada na análise social. Em 13 empresas (ALL, Banco do Brasil, Cemig, Copel, Dixie Toga, Duratex, Gerdau, Itaú, Souza Cruz, Suzano Papel e Celulose, TAM, Unibanco, WEG) os sites caracterizam-se como o mecanismo mais utilizado para a evidenciação. Salienta-se que em sete empresas (Banco Bradesco, Coelce, Companhia Vale do Rio Doce, CPFL Energia, Invepar, MAHLE Metal Leve, Ultrapar Participações) ocorreu empate entre os dois mecanismos de divulgação analisados.

\subsubsection{Evidenciação dos Elementos de Natureza Ambiental}

A matriz de elementos ambientais compõe-se de 11 elementos assim distribuídos nas três categorias de CI: quatro elementos na Competência do Funcionário, dois elementos na Estrutura Interna e cinco elementos na Estrutura Externa. Caso o total na última linha da matriz ambiental, tanto na análise dos RAs quanto na dos sites, fosse igual a 429 elementos (11 elementos x 39 empresas), corresponderia a 100\% de evidenciação de elementos ambientais. Os resultados totais por elementos ambientais são explanados na Tabela 6, assim como o percentual de evidenciação total por elemento.

Tabela 6: Resultados da Análise dos Elementos de CI de origem Ambiental

\begin{tabular}{|c|c|c|c|c|c|}
\hline \multirow{2}{*}{\multicolumn{2}{|c|}{ Elementos de Capital Intelectual Ambiental }} & \multicolumn{2}{|c|}{ Total } & \multicolumn{2}{|c|}{$\%$} \\
\hline & & RA s & site & RAs & site \\
\hline \multicolumn{6}{|c|}{ Competência do funcionário } \\
\hline 1 & Educação ou aprendizado ambiental & 23 & 17 & $59 \%$ & $44 \%$ \\
\hline 2 & Conhecimento de práticas de responsabilidade ambiental & 5 & 3 & $13 \%$ & $8 \%$ \\
\hline 3 & Competências relacionando o trabalho com a Responsabilidade Ambiental & 7 & 4 & $18 \%$ & $10 \%$ \\
\hline 4 & Conscientização Ambiental & 21 & 17 & $54 \%$ & $44 \%$ \\
\hline \multicolumn{6}{|c|}{ Estrutura Interna } \\
\hline 5 & Processos de Gestão Sustentáveis & 30 & 31 & $77 \%$ & $79 \%$ \\
\hline 6 & Processos de Captação e Minimização da emissão de resíduos (Reciclagem) & 32 & 31 & $82 \%$ & $79 \%$ \\
\hline \multicolumn{6}{|c|}{ Estrutura Externa } \\
\hline 7 & Ligação da Marca com a Responsabilidade Ambiental & 2 & 2 & $5 \%$ & $5 \%$ \\
\hline 8 & Conscientização ambiental dos Clientes & 22 & 26 & $56 \%$ & $67 \%$ \\
\hline 9 & Vinculação do nome ou da imagem com ações ambientais & 7 & 0 & $18 \%$ & $0 \%$ \\
\hline 10 & Integração e parcerias com a Comunidade & 28 & 28 & $72 \%$ & $72 \%$ \\
\hline 11 & Postura sustentável & 36 & 33 & $92 \%$ & $85 \%$ \\
\hline \multicolumn{2}{|c|}{ Total } & 213 & 193 & & \\
\hline
\end{tabular}

Fonte: Dados da Pesquisa 
$\mathrm{Na}$ análise da evidenciação dos elementos de CI de origem ambiental por meio dos RAs, obteve-se um total de 213 elementos, correspondendo a um percentual de evidenciação de 50\%. A divulgação através dos sites identificou-se um total de 193 elementos evidenciados, representando $45 \%$.

Observe-se que a evidenciação voluntária dos elementos de CI de natureza ambiental pelas empresas apresenta-se regular nos RAs, uma vez que se atingiu a marca de $50 \%$ de evidenciação dos elementos propostos pelo estudo. Já no que diz respeito à evidenciação voluntária dos elementos de CI de natureza ambiental por meio dos sites, se detectou um percentual menor, registrando $45 \%$ de evidenciação.

$\mathrm{O}$ elemento mais evidenciado em ambas as fontes de pesquisa foi 'Postura sustentável'. Outro elemento que obteve uma expressiva freqüência de evidenciação foi 'Processos de Capitação e Minimização da emissão de resíduos (Reciclagem)'. O elemento menos evidenciado nos RAs foi 'Conhecimento de práticas de responsabilidade ambiental', e o elemento 'Vinculação do nome ou da imagem com ações ambientais' não obteve nenhuma menção nos sites.

\subsubsection{Evidenciação dos Elementos de Natureza Ambiental por Categoria de CI}

A Estrutura Interna com $48 \%$ de representatividade apresenta-se como o componente de CI mais enfatizado na análise ambiental dos RAs. Em segundo lugar, com $30 \%$ de representatividade, identifica-se a Estrutura Externa. A Competência do Funcionário corresponde aos $22 \%$ restantes da evidenciação por categorias da análise dos RAs, conforme mostra a Ilustração 3.

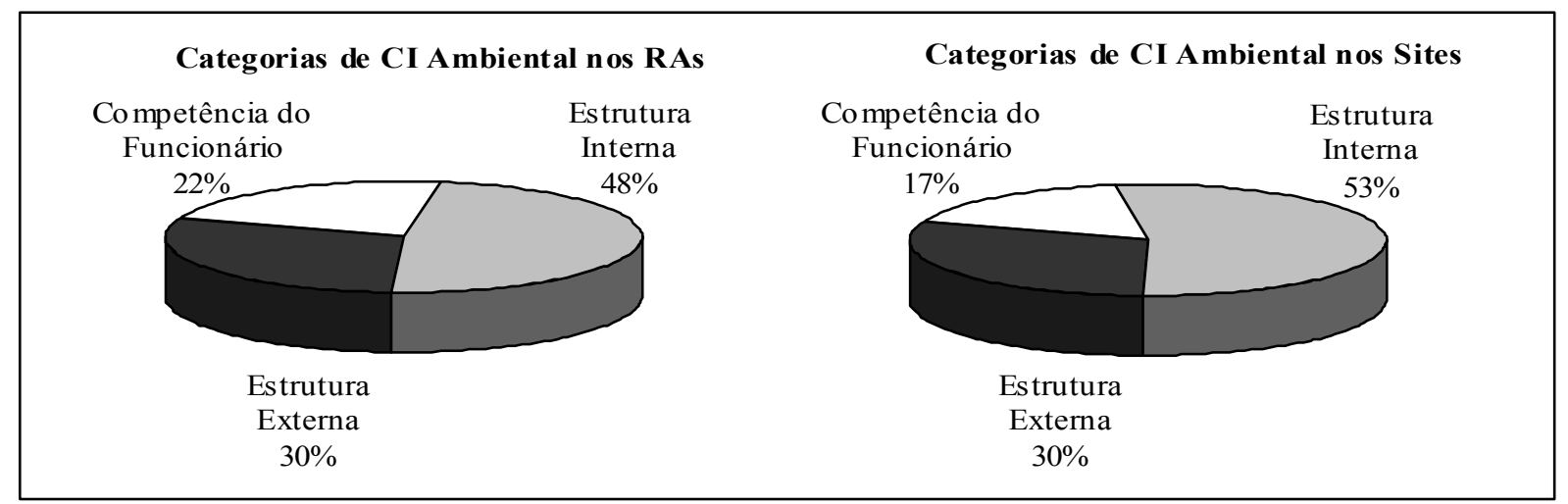

Ilustração 3: Representatividade por categoria de CI na análise ambiental dos RAs e dos Sites

Fonte: Dados da Pesquisa

Assim como o resultado obtido na observação dos RAs, a Estrutura Interna mantevese em primeiro lugar como a categoria com maior percentual de evidenciação na matriz de elementos ambientais na análise dos sites das empresas, com uma participação de $53 \%$. Resultado percentual mais expressivo identificado em todas as análises.

A Estrutura Externa obteve o segundo lugar com 30\% de evidenciação e a categoria Competência do Funcionário consolida-se como a menos representativa em todas as análises, sociais e ambientais. Salienta-se, ainda, a particularidade identificada nesta análise ambiental feita nos sites, no qual o resultado atingido pela Competência do Funcionário foi de 17\%, portanto, a menor participação percentual das análises. 


\subsection{Natureza da Evidenciação dos Elementos de CI}

Verificou-se que na totalidade da amostra investigada, utilizou-se da produção textual (narrativa) para evidenciar o CI. Para ilustrar esta constatação, reproduzem, a seguir, alguns exemplos de divulgação do CI extraídos dos RAs e dos sites da amostra pesquisada. O objetivo é ilustrar a natureza das divulgações do CI, a forma como foi realizada a leitura dos RAs e dos sites, como se procedeu a análise das informações e a conseqüente associação destas ao respectivo elemento com o qual estavam correlacionadas.

\subsubsection{Natureza da Evidenciação dos Elementos de CI na Análise Social}

Para ilustrar a categoria de CI de natureza social Competência dos Funcionários, apresenta-se a menção do elemento Educação ou aprendizado social extraída no Relatório de Sustentabilidade da Companhia Vale do Rio Doce.

A partir do entendimento de que a educação sustentável envolve o estímulo à autogestão da aprendizagem, a Vale investe na formação cidadã, capacitando as pessoas para continuarem a se desenvolver nos âmbitos pessoal, social e profissional (Relatório de Sustentabilidade 2006, p. 112, grifo nosso).

Em relação à Estrutura Interna, apresenta-se a sentença que identifica o elemento Cultura Organizacional Responsável no Relatório Anual da Sabesp.

Na Sabesp, a responsabilidade social é mais do que o somatório de ações sociais e ambientais. É um amplo conjunto de compromissos e práticas incorporados à sua cultura organizacional, às estratégias de seu negócio e ao modo ético de conduzir as suas operações, sempre com foco na sustentabilidade (Relatório da Administração de 2006, p.40, grifo nosso).

Na categoria de CI Estrutura Externa, a Energias do Brasil possui a seguinte menção do elemento Ligação da Marca com a Responsabilidade Social.

A logomarca do Grupo, criada internacionalmente em 2005, reflete a personalidade e os valores de uma empresa que tem sua estratégia baseada na sustentabilidade. É representada por um sorriso aplicado sobre fundo vermelho, que simboliza a proximidade com os clientes e o compromisso com a construção de uma sociedade mais inclusiva, que promova o bem-estar da população (Relatório Anual de 2006, p.56, grifo nosso).

\subsubsection{Natureza da Evidenciação dos Elementos de CI na Análise Ambiental}

A menção do elemento Competências relacionando o trabalho com a Responsabilidade Ambiental, apresentada pela empresa MAHLE Metal Leve, ilustra a natureza da evidenciação da Categoria de CI Competência dos Funcionários da análise ambiental.

O SGA (Sistema de Gestão Ambiental) integrado também tem plena consciência da evolução e da necessidade contínua de treinamento dos seus colaboradores em temas ambientais globais, entre eles, a mudança climática, a poluição das águas e do ar, a preservação da biodiversidade e a necessidade da racionalização do uso de recursos naturais (Site da Companhia em 09/02/2008, grifo nosso). 
No caso da categoria de CI Estrutura Interna da análise ambiental, tem-se o elemento Processos de Gestão Sustentáveis, cuja menção foi extraída no site da empresa Celulose Irani.

Dentro do programa de Gestão Ambiental, a IRANI identifica e analisa todos os aspectos e impactos ambientais de sua atividade produtiva. Desenvolve projetos de recuperação de áreas degradadas na área industrial e do aterro antigo (Site da Empresa em 26/01/2008, grifo nosso).

Relacionado à categoria de CI Estrutura Externa, apresenta-se o exemplo da menção do elemento Postura Sustentável, pela empresa Copel em seu site.

\begin{abstract}
Pioneira no Brasil em estudos e relatórios de impacto ambiental na construção de usinas hidrelétricas, a Copel vem ao longo dos anos implementando inúmeros programas voltados à conservação do meio ambiente. Atesta, na prática, seu compromisso com o desenvolvimento sustentável do Estado do Paraná (Site da empresa em 28/01/2008, grifo nosso).
\end{abstract}

Na seqüência da pesquisa apresenta-se a comparação entre os resultados obtidos nas análises sociais e ambientais.

\title{
Ambiental
}

\subsection{Comparação da Evidenciação dos Elementos de CI de Origem Social e}

$\mathrm{Na}$ análise dos RAs em relação ao percentual total de evidenciação dos elementos, a análise ambiental obteve um desempenho de $50 \%$ de evidenciação, e na análise social constatou-se um percentual de $45 \%$.

No que se refere à análise da evidenciação dos sites, o estudo dos elementos ambientais atingiu um resultado de $45 \%$ de evidenciação, enquanto a observação dos elementos sociais obteve $37 \%$ de evidenciação.

$\mathrm{Na}$ observação dos resultados obtidos nos RAs individualmente, 25 empresas da amostra demonstraram percentual superior de evidenciação dos elementos de origem ambiental, 13 empresas apresentaram maior freqüência de identificação de elementos de origem social e uma empresa não apresentou nenhum elemento proposto pelo estudo.

Os resultados constatados na análise dos sites foram bastante semelhantes aos anteriormente detectados, sendo que em 26 empresas ocorreu um maior percentual de evidenciação dos elementos de origem ambiental, e nas 13 empresas restantes, os resultados obtidos na intervenção social apresentam-se superiores.

Portanto, um aspecto relevante detectado ao cotejar os resultados das análises sociais e ambientais dos RAs e dos sites, foi que em ambas as fontes de pesquisa a evidenciação dos elementos ambientais obtiveram resultados superiores.

\section{CONSIDERAÇÕES FINAIS}

A pesquisa teve como principal objetivo identificar como é feita a evidenciação do CI de origem social e ambiental, e quais os elementos mais representados nas empresas pesquisadas. Nesse sentido, se propôs a analisar os Relatórios Anuais e de Sustentabilidade de 2006, denominados neste estudo como Relatórios Anuais (RAs), e os sites das 39 empresas integrantes do programa 'Em Boa Companhia' da Bolsa de Valores de São Paulo (BOVESPA). 
O estudo aponta a predominância da evidenciação por meio da forma textual com abordagem qualitativa tendo como resultado, narrativas que apresentam os elementos de CI de natureza social e ambiental por meio de menções explícitas ou implícitas.

Foi possível detectar a predominância da evidenciação de natureza ambiental nos RAs em 25 empresas da amostra, sendo que a Estrutura Interna foi a subdivisão mais representativa tanto na matriz social com $36 \%$, quanto na matriz ambiental com $48 \%$. No caso da análise dos sites 26 empresas apresentaram predominância para a evidenciação de elementos de natureza ambiental. Na matriz de elementos de origem social, a Estrutura Externa com $42 \%$ de evidenciação foi a categoria com maior representatividade desta análise. Do mesmo modo, na análise de elementos ambientais, a Estrutura Interna com 53\% da evidenciação destaca-se como a mais representativa. A categoria Competência do Funcionário registrou os menores percentuais de evidenciação em todas as análises procedidas pelo presente trabalho.

A revisão teórica apresentada possibilitou a reflexão entre a perspectiva do conceito de CI através da ótica da Responsabilidade Social, permitindo conciliar estas duas abordagens diante da atual necessidade competitiva das empresas, em que estas precisam adequar os aspectos econômicos e de mercado com o desenvolvimento responsável e sustentável, comprometido com as questões sociais e ambientais.

O trabalho permitiu identificar uma evidenciação média nos RAs de $48 \%$ em relação ao total possível de evidenciação, sendo que os elementos sociais apresentaram $45 \%$, e os elementos ambientais 50\%. Já nos sites a média da evidenciação total foi de $41 \%$, com $37 \%$ de evidenciação dos elementos sociais e $45 \%$ dos ambientais. Os elementos mais identificados na pesquisa foram: 'Projetos e ações de incentivo a prática educacional' com $95 \%$ de evidenciação tanto nos RAs quanto nos sites, e 'Integração e Parcerias com a comunidade' com $92 \%$ nos RA e $95 \%$ nos sites, ambos na matriz social. Na matriz de elementos de origem ambiental o elemento com maior número de identificações foi 'Postura sustentável' com 92\% nos RAs e $85 \%$ nos sites.

\section{REFERÊNCIAS}

ASHLEY, P. A. (coord.). Ética e responsabilidade social nos negócios. 2 ed. São Paulo: Saraiva, 2005.

BARDIN, L. Análise de conteúdo. Lisboa: edições 70, 2004.

BOVESPA. Bolsa de Valores de São Paulo. Disponível em: $<$ http://www.bovespa.com.br/Principal.asp $>$. Acesso em: 20 out. 2007.

BRENNAN, N. Reporting intellectual capital in annual reports: evidence from Ireland. Accounting, Auditing \& Accountability Journal. Bradford, vol. 14, n. 4, p. 423-437, 2001.

CAMPOS, F. M. de; LEMME, C. F. Exame da metodologia dos índices internacionais do mercado acionário e da experiência brasileira na área do investimento socialmente responsável. In: Encontro Nacional Sobre Gestão Empresarial e Meio Ambiente - IX Engema, 2007, Curitiba. Anais... 2007. CD-ROM.

CARVALHO, F. N. de; ENSSLIN, S. R.; IGARASHI, D. C. C. Evidenciação Voluntária do Capital Intelectual no Contexto Brasileiro: Cotejamento com os Contextos Internacional e Australiano. In: ENANPAD, 30, 2006, Curitiba. Anais... Salvador: ANPAD, 2006. CD-ROM. 
CERVO, A. L.; BERVIAN, P. A. Metodologia científica. 3 ed. São Paulo: Mc Graw - Hill do Brasil, 1983.

CHEN GOH, P.; PHENG LIM, K.. Disclosing intellectual capital in company annual reports: evidence from Malaysia. Journal of Intellectual Capital. Bradford, vol. 5, n. 3, p. 500-511, 2004.

CRAWFORD, R. Na era do capital humano: o talento, a inteligência e o conhecimento como forças econômicas, seu impacto nas empresas e nas decisões de investimentos. São Paulo: Atlas, 1994.

EDVINSSON, L.; MALONE, M; S. Capital intelectual: descobrindo o valor real de sua empresa pela identificação de seus valores internos. São Paulo: Makron Books, 1998.

ENSSLIN, S. R.; CARVALHO, F.N. Voluntary disclosure of intellectual capital in the Brazilian context: an investigation informed by the international context. Int. J. Accounting, Auditing and Performance Evaluation, v. 4, n. 4/5, p. 478-500, 2007.

KAPLAN, R. S.; NORTON, D. P. Mapas estratégicos: Convertendo ativos intangíveis em resultados tangíveis. Rio de Janeiro: Campus, 2004.

KLEIN, D. A. A gestão estratégica do capital intelectual: Recursos para a economia baseada em conhecimento. Rio de Janeiro: Qualitymark, 1998.

PUGLISI, M.L.; FRANCO, B. Análise de conteúdo. 2. ed. Brasília: Líber Livro, 2005.

RICHARDSON, R. J. Pesquisa social: métodos e técnicas. São Paulo: Atlas, 1999.

SCHENINI, P. C. (org.). Gestão empresarial sócio ambiental. Florianópolis: (s.n), 2005.

SEFFERT, M. E. B. ISO 14001 Sistemas de Gestão Ambiental: Implantação objetiva e econômica. São Paulo: Atlas, 2005.

SILVA FILHO, F. F. D. da. Responsabilidade socioambiental como paradigma contemporâneo. In: Encontro Nacional Sobre Gestão Empresarial e Meio Ambiente - IX Engema, 2007, Curitiba. Anais... 2007. CD-ROM.

SOARES, R. C. Empresariedade e ética: o exercício da Cidadania Corporativa. São Paulo: Atlas, 2002.

STEWART, T.s A. Capital intelectual: a nova vantagem competitiva nas empresas. Rio de Janeiro: Campus, 1998.

SVEIBY, K. E. A nova riqueza das organizações: gerenciando e avaliando patrimônios de conhecimento. Rio de Janeiro: Campus, 1998. 